\title{
Altered calcitonin gene in a young patient with osteoporosis
}

\author{
M Alevizaki, J C Stevenson, S I Girgis, I MacIntyre, S Legon
}

\begin{abstract}
To assess whether calcitonin is important in maintaining the integrity of bone the calcitonin gene of a young male patient with osteoporosis and no detectable plasma concentrations of calcitonin was studied. Genomic Southern blots with various restriction enzymes showed no large abnormalities in his calcitonin gene. Genomic clones representing his calcitonin gene were then analysed. His gene encoded normal precursor polypeptides for calcitonin and calcitonin gene related peptide; the only abnormality identified was a single base insertion in the intron separating exons IV and $\mathrm{V}$ of the gene. The affected sequence is homologous with an intron sequence from $\beta$ globin that is implicated in splicing and forming a crucial intermediate structure during the maturation of messenger RNA.

The change observed may be responsible for the patient's calcitonin deficiency and consequently for his condition, suggesting that calcitonin is important in preventing bone loss.
\end{abstract}

\section{Introduction}

Whether calcitonin has an important role in maintaining skeletal integrity is not known. ${ }^{12}$ One finding supporting such a role was the identification of a young male patient with severe osteoporosis who was completely deficient in calcitonin and has responded well to calcitonin replacement treatment over the past nine years. ${ }^{3}$ We therefore considered the possibility that his calcitonin gene might be defective. As the C cells of the thyroid are not accessible for direct analysis of calcitonin gene expression we instead carried out a detailed structural study of the gene looking for any changes that might explain this failure to produce calcitonin.

\section{Materials and methods}

DNA was extracted from the patient's peripheral lymphocytes ${ }^{4}$ and after restriction enzyme digestion was analysed on Southern blots probed with labelled restriction fragments specific for either calcitonin or calcitonin gene related peptide. Probe fragments were derived from the clones phTB3 $3^{5}$ and phTB58 $8^{6}$ and contained only exon IV or exon V and VI sequences

BrMed f 1989;298:1215-6. from the human $\alpha$ calcitonin-calcitonin gene related peptide gene (see fig 1). DNAs were labelled with phosphorus-32 by random primed synthesis ${ }^{7}$ to $10^{9}$ disintegrations per minute/ $\mu \mathrm{g}$ and blots were hybridised and washed under stringent conditions as previously. ${ }^{8}$ Genomic DNA was cloned into the Bam $\mathrm{Hl}$ site of phage lambda EMBL4 and two independent clones were identified with a probe specific for calcitonin. Suitable regions were subcloned into $M 13$ vectors and sequences were determined with the chain termination method. In all cases both strands were sequenced.

\section{Results and discussion}

THE CALCITONIN GENE

The calcitonin gene is complex and many details about how its expression is regulated remain unclear. Calcitonin is produced by proteolytic cleavage of a pre-prohormone, which also includes $\mathrm{N}$ and $\mathrm{C}$ terminal flanking peptides and a short signal peptide (fig 1). In the calcitonin gene the sequences representing calcitonin messenger RNA are found in four blocks (exons): exon I contains non-coding sequences from the beginning of the messenger RNA, exon II encodes the signal peptide, exon III encodes the $\mathrm{N}$ terminal flanking peptide, and exon IV encodes calcitonin itself, the $\mathrm{C}$ terminal flanking peptide, and the non-coding sequences from the end of the messenger RNA. When calcitonin messenger RNA is being made the synthesis of RNA starts at exon I and continues through the entire gene, ending several thousand bases beyond the end of exon IV. This primary transcript is then cut and reassembled in a complex series of splicing reactions, which result in the formation of the mature messenger RNA, which includes only the sequences of the first four exons (fig 1).

This type of organisation is common to almost all human genes. The calcitonin gene is unusual in that it can give rise to a second messenger RNA encoding another regulatory peptide known as calcitonin gene related peptide. ${ }^{9}$ When this peptide is produced the primary transcript undergoes an alternative series of splicing reactions, which result in the assembly of a messenger RNA comprising exons I, II, and III joined to two further exons, V and VI (fig 1). Exon V encodes calcitonin gene related peptide and its $C$ terminal flanking peptide, and exon VI is non-coding.

A second calcitonin gene related peptide exists in the human genome: $\beta$ calcitonin gene related peptide is encoded by a related gene in which the equivalent of the calcitonin coding exon is no longer functional. ${ }^{8}$ Plasma calcitonin gene related peptide concentrations in our patient were normal, and he showed no symptoms that might suggest loss of this peptide, which is believed to have an important role in maintaining vascular tone. Although our immunoassay cannot distinguish between the two forms of calcitonin gene related peptide, both are probably present because differing distributions in tissue suggest complementary rather than duplicated activities. In considering the type of changes that might cause our patient's condition, changes that would prevent the correct expression of calcitonin while leaving the
$\begin{array}{cccccccc}\mathrm{S} & \mathrm{N}-\mathrm{F} & \mathrm{CT} & \mathrm{C}-\mathrm{F} & \mathrm{S} & \mathrm{N}-\mathrm{F} & \mathrm{CGRP} & \mathrm{C}-\mathrm{F} \\ \text { FIG } 1-\text { Calcitonin-calcitonin gene related peptide gene. Numbers refer to exons of gene. } S=\text { Signal peptide, }\end{array}$ $N-F=$ amino terminal flanking peptide, $C T=$ calcitonin, $C-F=$ carboxy terminal flanking peptide, and $C G R P=$ calcitonin gene related peptide 


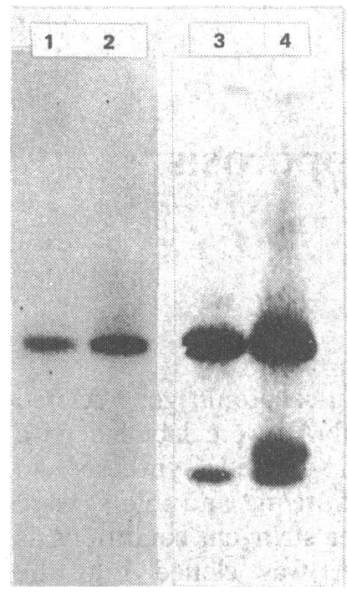

FIG 2-Southern blot analysis of calcitonin-calcitonin gene related peptide gene. Samples of DNA from patient (lanes 1 and 3 ) and control subject (lanes 2 and 4) were digested with restriction enzyme Taq 1 and analysed by Southern blotting, probing the filters with probe specific for calcitonin (1 and 2) or calcitonin gene related peptide ( 3 and 4 ).

Lower band in track 4 is doublet. Control subject has a previously unreported polymorphism in this part of gene expression of calcitonin gene related peptide largely unaffected seem more likely. The simplest such change would be an alteration to the DNA sequence of exon IV.

\section{DNA SEQUENCE OF CALCITONIN GENE}

As a first step in the analysis of our patient's calcitonin-calcitonin gene related peptide gene we looked for large structural changes in the region of exon IV by using the technique of Southern blotting (fig 2). With this procedure changes can be seen in the lengths of restriction fragments of the DNA that may result from insertion or deletion of sequences in the region being analysed. The method provides a rapid analysis but is limited in that changes of fewer than 20 bases are not detectable. No differences; quantitative or qualitative, were seen between our patient's calcitonin gene and that of controls. For a more detailed analysis we isolated the calcitonincalcitonin gene related peptide gene from DNA prepared from our patient's peripheral lymphocytes. The entire DNA sequence encoding pre-procalcitonin was determined and corresponded exactly with the published gene sequence. Further analysis showed that the parts of the gene specific for calcitonin gene related peptide (exons V and VI) were also entirely normal.

We then focused on the regions important for the differential processing of messenger RNAs for calcitonin and calcitonin gene related peptide. During the process of splicing the precursor RNA is cleaved after one exon, and the intervening sequence (intron) then forms a looped structure before cleavage at the second exon, joining of the two exon sequences, and elimination of the intervening sequence (fig 3 ).

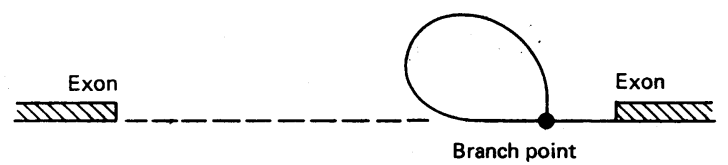

FIG 3-Formation of looped structure during maturation of messenger RNA precursors. First step in eliminating intervening sequence is cleavage after first exon and looping back to branch point

The important regions are those at the ends of the intervening sequence and at the branch point where the looped structure forms..$^{10}$ In the particular case of the calcitonin-calcitonin gene related peptide gene cleavage of the precursor RNA at the end of the calcitonin exon (IV) is important in preventing the splice that leads to production of calcitonin gene related peptide ${ }^{11}$ and further evidence suggests that the secondary structure of the precursor RNA is important in allowing its interaction with exon specific splicing factors. ${ }^{12}$

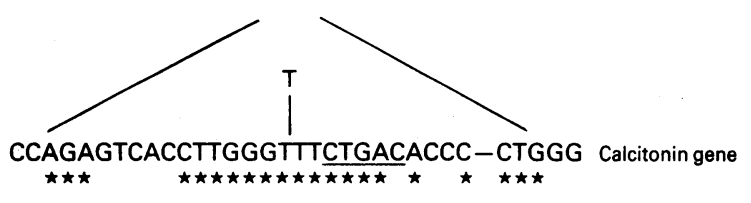

AGAGAAGACTCTTGGGTTTCTGATAGGCACTGAC $\beta$ Globingene

FIG 4-Altered calcitomin gene sequence from patient with osteoporosis. Sequence from intervening sequence between exons IV and $V$ shows single base insertion, which is next to consensus sequence for formation of branch point (CTGAC (underlined)) and has homology with more extensive sequence from branch point in the $\beta$ globin gene. Asterisks show identical residues in calcitonin and $\beta$ globin genes
When our patient's DNA was sequenced no changes were found in these critical regions. The only difference between our sequence and the normal sequence was a single base insertion at position 462 in the intervening sequence between exons IV and V (fig 4). Such a finding was not unexpected as non-coding sequences such as these commonly show differences (neutral polymorphisms) between individual people and these differences have no effect on the expression of the neighbouring genes. The extra base is, however, next to a CTGAC sequence, which is the consensus sequence for formation of a branch point during splicing. ${ }^{10}$ We searched the GENBANK database of DNA sequences for similar sequences. Out of more than 10 million bases in the database, the best fit was with a short sequence from the $\beta$ globin gene, which has been shown to become resistant to ribonuclease during in vitro splicing and is the site for formation of a branch point (fig 4)..$^{13}$

This homology indicates that the altered sequence in our patient may participate in splicing reactions. It is, however, unlikely to be the primary branch point site in this intervening sequence as these are generally much closer to the following exon sequence. Further studies with the gene in an in vitro expression system would be necessary to determine how any effect is produced. One possibility is that the altered sequence takes on the properties of a branch point, forcing an abortive splice which precludes the production of calcitonin.

Establishing a role for calcitonin in the aetiology of this patient's osteoporosis is of considerable importance. Although his condition is undoubtedly rare, the results suggest that calcitonin plays an important part in maintaining skeletal integrity, strengthening arguments in favour of its use in treating osteoporosis in general.

We thank the Hammersmith and Queen Charlotte's Special Health Authority for its support of this work.

1 McDermot MT, Kidd GS, Blue P, Ghaed V, Hofeld FD. Reduced bone mineral content in totally thyroidectomised patients: possible effect of calcitonin deficiency. 7 Clin Endocrinol Metab 1983;56:936-9.

2 Hurley DL, Tiegs RD, Wahner HW, Heath $H$. Axial and appendicular bone mineral density in patients with long term deficiency or excess of calcitonin. M Engl f Med 1987;317:537-41.

3 Stevenson JC, White MC, Joplin JF, MacIntyre I. Osteoporosis and calcium deficiency. Br Med f 1982;285:1010-1.

4 Foroni L, Foldi J, Matutes E, et al. Alpha, beta and gamma T cell receptor genes: rearrangements correlate with haematological phenotype in T-cell 1987:67:307-18.

5 Craig RK, Hall L, Edbrooke MR, Allison J, MacIntyre I. Partial nucleotide sequence of human calcitonin precursor mRNA identifies flanking cryptic peptides. Nature 1982;295:345-7.

6 Edbrooke MR, Parker D, McVey JR, et al. Expression of the human calcitonin/CGRP gene in lung and thyroid carcinoma. EMBO $\mathcal{f}$ 1985; 715-24.

7 Feinberg AP, Vogelstein B. A technique for radiolabelling DNA restriction endonuclease fragments to high specific activity. Anal Biochem 1983;132: 6-13.

8 Alevizaki M, Shiraishi A, Rassool FV, Ferrier GJM, MacIntyre I, Legon S The calcitonin like sequence of the beta CGRP gene. FEBS Lett 1986;206: 47-52.

9 Jonas V, Lin CR, Kawashima E, et al. Alternative RNA processing events in human calcitonin/CGRP gene expression. Proc Natl Acad SciUSA 1985;82: 1994-8.

10 Konarska MM, Grabowski PJ, Padgett RA, Sharp PA. Characterisation of the branch site in lariat RNAs produced by splicing of mRNA precursors. Nature 1985;313:552-7.

11 Bovenberg RAL, van den Meerendonk WPM, Baas PD, Steenbergh PH, Lip CJM, Jansz HS. Model for alternative RNA processing in human calcitoni gene expression. Nucleic Acids Res 1986;22:8785-803.

12 Leff SE, Evans RM, Rosenfeld MG. Splice commitment dictates neuro specific alternative RNA processing in calcitonin/CGRP gene expression. Cell 1987;48:517-24.

13 Ruskin B, Green MR. Specific and stable intron:factor interactions are established early during in vitro pre-mRNA splicing. Cell 1985;43:131-42.

(Accepted 14 February 1989) 